\title{
The Amplification of Gravitational Waves and Creation of Gravitons in the Isotropic Universes.
}

L. P. GrisirchuK

Sternberg Astronomical Institute - Moscow

(Lett. Nuovo Cimento, 12, $60(1975)$ )

Some minor errors alter the original sense of the paper. They are:

1) Page 62, sixth line from above. It is printed $|A|^{2}-|B|^{2}=0$ instead of $|A|^{2}-|B|^{2}=$ const.

2) Page 62, eighteenth line from above. It is printed $A_{1}=0$ instead of $A_{1} \neq 0$

(C) by Soclots Italiana di Fisica

Proprieta lotteraria ribervata

Direttore responsabile: CARLO CASTAGNOLI

Stampato in Bologna dalla Tipografla Compositori coi tipi dolla Tipografia Monograf Questo fascicolo stato licenziato dai torehi l' 11-III-1975 